\title{
Narrativas de uma professora em final de carreira: a educação frente à pandemia
}

\section{Narratives of a teacher at the end of her career: education in the face of the pandemic}

\author{
Juliana Pedroso Bruns \\ Mestranda em Educação - Bolsista CAPES \\ Fundação Universidade Regional de Blumenau - (PPGE-FURB) \\ Blumenau, SC - Brasil. \\ julianap.bruns@gmail.com
}

iD Rita Buzzi Rausch

Doutora em Educação (UNICAMP)

Professora visitante da Fundação Universidade Regional de Blumenau - (PPGE-FURB) e da Universidade da Região de Joinville (PPGE-UNIVILLE)

Blumenau, SC - Brasil. ritabuzzirausch@gmail.com

Resumo: Com vistas a valorizar os saberes docentes de uma professora em final de carreira, refletiu-se sobre a formação de professores e a utilização das tecnologias digitais no processo de ensino e aprendizagem, mediante e-learning, no momento em que o país vivencia uma pandemia mundial provocada pelo COVID-19. Realizou-se uma pesquisa qualitativa e, para coleta dos dados, utilizou-se entrevista narrativa com uma professora em final de carreira, que atua na Rede Municipal de Ensino de Brusque, (SC). Para análise, utilizou-se a análise de conteúdo e como suporte teórico, as contribuições de Marcelo (2001), Vaillant e Marcelo (2012), Nóvoa (2009, 2019, 2020) e Pérez Gómez (2015). Os resultados evidenciaram lacunas na formação continuada, pois não basta propiciar aos docentes formação, bem como utilizar tecnologia para o processo de ensino aprendizagem, visto que muitos estudantes não possuem acesso à internet. Tornando-se urgente repensar a educação, principalmente, das crianças pertencentes às classes menos privilegiadas.

Palavras-chave: E-learning. Formação continuada. Tecnologias digitais.

Abstract: With a view to valuing the teaching knowledge of a teacher at the end of her career, she reflected on teacher training and the use of digital technologies in the teaching and learning process, through e-learning, at a time when the country is experiencing a pandemic. caused by COVID-19. A qualitative research was carried out and, for data collection, a narrative interview was used with a teacher at the end of her career, who works at the Municipal Education Network of Brusque, (SC). For analysis, content analysis was used and as theoretical support, the contributions of Marcelo (2001), Vaillant and Marcelo (2012), Nóvoa (2009, 2019, 2020) and Pérez Gómez (2015). The results showed gaps in continuing education, as it is not enough to provide teachers with training, as well as to use technology for the teaching-learning process, since many students do not have access to the internet. It is becoming urgent to rethink the education, especially of children belonging to the less privileged classes.

Keywords: E-learning. Continuing education. Digital technologies. 


\section{Introdução}

As narrativas pessoais de uma professora no final de sua carreira docente, durante um período atípico ocasionado pela "pandemia do coronavírus", pode contribuir para uma reflexão sobre a utilização de tecnologia digital como ferramenta no processo de ensino e aprendizagem dos estudantes e também indicar o que precisa ser revisto para a formação continuada de professores. Ressalta-se que, por conta da pandemia foi decretado estado de calamidade pública nos termos da solicitação do Presidente da República encaminhada por meio da Mensagem $\mathrm{n}^{\circ}$ 93, de 18 de março de 2020 (BRASIL, 2020a), e as aulas presenciais foram suspensas por meio da Portaria no 343, de 17 de março de 2020, publicada igualmente em 18 de março, em caráter excepcional, sendo substituídas por aulas online, que utilizem meios e tecnologias de informação e comunicação, nos limites estabelecidos pela legislação em vigor (BRASIL, 2020b).

Tal determinação exigiu dos docentes e estudantes mudanças significativas no processo de ensino e aprendizagem. Torna-se impossível, como expõe Nóvoa (2009), ignorar o impacto da revolução digital, o que implica em novas concepções de ensino e aprendizagem, demandando dos docentes uma nova postura frente à utilização das tecnologias. Vaillant e Marcelo (2012), do mesmo modo, observam que uma das características mais visíveis do século XXI são as sociedades com estrutura em rede e subordinadas ao conhecimento e as tecnologias digitais e um dos principais valores de seus cidadãos é o conhecimento, que está diretamente relacionado ao nível de formação e a capacidade de inovação que eles possuem.

Assim elucidado, infere-se que, com a chegada das tecnologias no cenário educativo, coloca-se em evidência inúmeros desafios, sobretudo, aos professores e estudantes, mas também visualizam-se muitas oportunidades, como observam Vaillant e Marcelo (2012), a educação mediante e-learning constitui um caminho ao alcance da mão e pode propiciar reformas e inovações que tenham como eixo central o direito de aprender que todos os estudantes possuem. Tudo isso, portanto, leva-se a refletir acerca do papel dos docentes nesse novo cenário educativo.

Desse modo, com vistas a valorizar os saberes docentes de uma professora em final de carreira, a pesquisa buscou-se refletir sobre a formação de professores e a utilização das tecnologias digitais nos processos de ensino e aprendizagem. A pesquisa faz parte de um estudo mais aprofundado realizado com professoras alfabetizadoras experientes e, a escolha da entrevistada, justifica-se pelo tempo de docência exercido e também por sua experiência na 
alfabetização atuando na Rede Municipal de Ensino de Brusque (SC), local onde realizou-se a pesquisa. A participante concordou em fazer parte desta reflexão e expor como vem se sentindo frente às mudanças que, em um curto espaço de tempo, as escolas tiveram que se adequar no momento em que as aulas passaram a ser oferecidas por meio de plataformas digitais.

A seguir, revela-se o percurso metodológico utilizado no desenvolvimento desta pesquisa. Posteriormente, elucida-se a respeito da formação continuada de professores mediante e-learning, para tal, utiliza-se as contribuições de Vaillant e Marcelo (2012), Marcelo (2010) e Nóvoa (2009). Em seguida, apresenta-se a análise dos resultados da pesquisa, com respaldo principalmente em Vaillant e Marcelo (2012), Nóvoa (2009, 2020) e Pérez Gómez (2015), seguida das considerações finais.

\section{Percurso metodológico}

A pesquisa caracteriza-se como de abordagem qualitativa pelo fato de privilegiar os sentidos, os dizeres e "a voz" de uma professora em final de carreira. O campo empírico localiza-se nos anos inicias do Ensino Fundamental, mais precisamente em uma escola da Rede Municipal de Ensino de Brusque, (SC).

André (2013) observa que as abordagens qualitativas de pesquisa se baseiam numa perspectiva que concebe o conhecimento como um procedimento socialmente construído pelos sujeitos nas suas interações cotidianas. Igualmente, Bogdan e Biklen (1994) observam que a pesquisa qualitativa também é descritiva, pois busca descrever dados, fazendo com que as palavras assumam significativo valor.

Com relação ao instrumento utilizado para geração de dados, optou-se pela entrevista narrativa. $\mathrm{O}$ gênero discursivo apresenta maior aproximação com o objetivo da pesquisa, pois ao valorizar as narrativas da professora escolhida reflete sobre a formação de professores e a utilização das tecnologias digitais nos processos de ensino e aprendizagem. Prado e Soligo (2007, p. 48) expõem que a entrevista narrativa "supõe uma sequência de acontecimentos, é um tipo de discurso que nos presenteia com a possibilidade de dar à luz o nosso desejo de os revelar".

Para preservar-se a saúde de todos envildos na pesquisa e obedecendo ao decreto promulgado que estabelece que as aulas sejam oferecidas mediante os meios e tecnologias de informação e comunicação (BRASIL, 2020b), a presente entrevista foi realizada por meio do celular, utilizando o aplicativo de comunicação "WhatsApp" atreavés de mensagens de áudio. 


\section{Dialogia}

BRUNS, Juliana Pedroso; RAUSCH, Rita Buzzi. Narrativas de uma professora em final de carreira: a educação frente à pandemia

Como o objetivo de assegurar os aspectos éticos, no que envolve a conduta das pesquisadoras em relação ao fato pesquisado e a dignidade humana da participante, a pesquisa está resguardada eticamente sob o Certificado de Apresentação para Apreciação Ética (Caae), número 22928619.5.0000.5370, aprovado pelo Comitê de Ética e Pesquisa (CEP) por meio da submissão na Plataforma Brasil. No que diz respeito à identificação da participante, a professora optou por utilizar seu apelido (Nice), pois as pessoas conhecem-na assim.

A análise dos dados ocorreu mediante a análise de conteúdo. Bardin (2016) observa que a análise de conteúdo é um conjunto de técnicas que possibilitam a análise das comunicações, colocando-as em evidência para o desvelamento dos significados do conteúdo. Na presente pesquisa, foram realizados os seguintes procedimentos: a organização da documentação, compreendida como a transcrição da entrevista narrativa e a exploração e análise dos dados qualitativos. Em seguida, foi realizada a interpretação dos resultados, para isso, os dados foram relacionados e distanciados, e- confrontados com o referencial teórico existente. No quadro a seguir, apresenta-se o perfil da professora participante da pesquisa.

\begin{tabular}{|c|c|c|}
\begin{tabular}{|} 
Quadro 1 - Perfil da professora em final de carreira participante da pesq \\
Professora
\end{tabular} & $\begin{array}{c}\text { Magistério e } \\
\text { Graduação }\end{array}$ & $\begin{array}{c}\text { Horas Aula de } \\
\text { Trabalho }\end{array}$ \\
\hline Nice & $\begin{array}{c}\text { Possui Magistério e } \\
\text { Graduação em } \\
\text { Pedagogia } \\
\text { Especialização } \\
\text { (Lato Sensu) }\end{array}$ & $\begin{array}{c}\text { Aposentada } \\
\text { (Em serviço) }\end{array}$ \\
\hline Idade & $\begin{array}{c}\text { Tempo de Serviço } \\
\text { na Educação }\end{array}$ \\
\hline 68 anos & Séries Iniciais & 51 anos \\
\hline
\end{tabular}

Fonte: Produzido pelas pesquisadoras (2020)

Ressalva-se que a professora é a alfabetizadora experiente com mais tempo de serviço na educação na Rede Municipal de Ensino, possuindo 51 anos de serviço.

\section{Formação continuada de professores: reflexões mediante $e$-learning}

A incorporação das tecnologias da informação e da comunicação, conforme expõem Vaillant e Marcelo (2012), evoluiu no decorrer dos últimos anos. Foi desse modo que se passou da teleaprendizagem nos 1900 a e-learning nos anos 2000. Observa-se que o e-learning abarca uma grande variedade de possíveis experiências educativas a distância, possibilitando o desenvolvimento de formação para os docentes e para estudantes que se encontram em espaços 
físicos diferentes, mas que conseguem se comunicar. Trata-se, portanto "de uma modalidade que permite utilizar as potencialidades da rede para aproximar a formação aos docentes e, por sua vez, implementar novos cenários capazes de flexibilizar e ampliar as suas experiências de formação" (VAILLANT; MARCELO, 2012, p. 204).

Marcelo (2001) observa que, atualmente, há um grande processo de transformação que vem afetando e modificando a forma como os sujeitos trabalham, relacionam-se e aprendem. Tais mudanças; estão repercutindo diretamente na escola que, enquanto instituição educativa, é encarregada de formar os novos cidadãos. Nota-se, que muitos estudantes dispõem de um número significativo de fontes de informação, o que não ocorria há cerca de 10 anos. Essas mudanças estão exigindo das instituições educativas adaptações no que se refere à formação continuada dos professores. Nesse viés, o autor supracitado observa não ser possível, portanto, esperar que a formação inicial seja capaz de suprir todas as necessidades encontradas ao longo de um percurso profissional ativo, visto que a constante mudança ocasionada pelo acelerado desenvolvimento tecnológico na sociedade do conhecimento requer das pessoas atitudes de permanente aprendizagem.

Nóvoa (2019) já havia abordado em seus estudos sobre uma "metamorfose da escola". Configurando-se, para o autor, como um período marcado por profundas transições na área da Educação. Um tempo que requer, sobretudo, dos docentes uma nova posição apressada frente às mudanças provocadas pela pandemia do coronavírus. Entretanto, poder-se-á encontrar algumas resistências quanto as mudanças, pois a escola como a conhecemos, consolidou-se por volta do século XIX, há cerca de 150 anos, e difundiu-se em todo o mundo um modelo que, apesar das críticas, resiste até os dias atuais. Nas palavras do autor "todos conhecem as características deste modelo escolar. A sua força é tal que já nem sequer conseguimos imaginar outras formas de educar" (NÓVOA, 2019, p. 2).

Vaillant e Marcelo (2012, p. 204) observam que o e-learning apresenta múltiplas vantagens, por exemplo, o "acesso inteligente à informação, personalização do aprendizado, acesso sem fronteiras à formação, atualização dos conteúdos”. Entretanto, essas vantagens são acompanhadas de algumas críticas como, por exemplo, à falta de contatos presenciais ou a utilização de algumas ferramentas. Além disso, muitos docentes narram que "aprender a distância" é impessoal e temem perder o calor humano ao não estarem fisicamente com os estudantes. Nesse sentido, Vaillant e Marcelo (2012, p. 205) refletem que "é necessário levar em consideração essas dificuldades e resistências, mas também é preciso admitir a enorme potencialidade do e-learning", sobretudo, em tempos de isolamento social, a formação e o 
ensino mediante a utilização das tecnologias digitais crescem de forma exponencial, pois "novos tempos e novas práticas requerem dos docentes novos perfis" (VAILLANT; MARCELO, 2012, p. 208).

Esse tipo de formação, como observam Vaillant e Marcelo (2012), demanda do docente o rompimento de algumas crenças a respeito dos processos de ensinar e aprender, exigindo uma mudança na prática, bem como de conhecimentos e concepções sobre sua tarefa profissional e sua própria identidade profissional docente. Além disso, a comunicação entre docente e estudantes em um ambiente on-line "diferencia-se da comunicação presencial, na qual a distinção entre falante/escritor e ouvinte/leitor não é tão clara. A distinção entre linguagem falada e escrita muda, e ocorrem também algumas diferenças que afetam a interação. (VAILLANT; MARCELO, 2012, p. 210).

Vaillant e Marcelo (2012) afirmam que há um elemento chave que facilita ou dificulta o envolvimento de um docente com as tecnologias, a compatibilidade entre as crenças pedagógicas e sua utilização. Crenças que perpassam todo o percurso formativo e profissional do docente.

Os estudos sobre as crenças que os docentes trazem consigo, coloca em evidência que aqueles que são mais reflexivos e conscientes de suas próprias crenças pedagógicas são comumente os mais flexíveis. Comprova-se, então, que é mais provável haver êxito na utilização das tecnologias se os docentes tiverem o hábito de refletir sobre sua própria prática pedagógica. Portanto, se as crenças pedagógicas forem consistentes com as tecnologias, os docentes empenhar-se-ão para utilizá-las e, assim, conseguirão resultados positivos com os estudantes.

Entretanto, infere-se que, por vezes, tais crenças podem ser mais difíceis de se modificarem, principalmente se os professores estão há mais tempo na educação e fazem parte de uma geração que precede a ascensão e a utilização das tecnologias no processo educativo dos estudantes, o que se torna um desafio ainda maior o manejo das ferramentas tecnológicas. Alguns desses desafios, poderão ser evidenciados na narrativa da professora participante desta pesquisa. 


\title{
Narrativas de uma professora em final de carreira
}

Nice, ao narrar sua vivência enquanto docente no cenário atual, relata que a dinâmica de lecionar virtualmente e ter que fazer uso de ferramentas tecnológicas é muito diferente e que embora tenha mais de 50 anos de docência e esteja no final de sua carreira docente, expõe:

\begin{abstract}
Ah ... é uma dinâmica toda diferente né, é diferente, por exemplo, uma coisa que eu ... agora ainda mais com esse distanciamento né, eu sou idosa então eu tenho que ficar mais ainda confinada, tanto é que meus filhos é que trazem tudo que eu preciso e vão no mercado pra mim, porque eles não querem que eu saia de casa. Ah ... me deu um desespero muito grande [...], quando veio a notícia de que a gente daria aula on-line, aí quando eu comecei a fazer aquele curso do Moodle, é ... eu fiquei um dia todo tentando entrar, eu não conseguia entrar pra fazer o curso e com a ajuda de um professor ainda, do professor de informática da nossa escola.
\end{abstract}

Diante da narrativa da professora Nice, fica visível as dificuldades que assim como ela, muitos docentes podem estar vivenciando, no momento em que as aulas presenciais foram substituídas pelas aulas ministradas por meio de tecnologias digitais. Além disso, com a mudança repentina, as escolas e os professores tiveram que se adequar a essa nova modalidade de ensino e muitos estão tendo que "aprender" a utilizar as tecnologias rapidamente, algo que, para muitos docentes, não fazia parte da realidade ou, quando fazia, estavam na instituição escola e podiam recorrer ao auxílio de professores que possuíam mais "facilidade", por assim dizer, no manejo de equipamentos tecnológicos. Nice expõe:

Eu sei que naquela tarde eu chorei um monte e me deu um desespero muito grande e aí eu sei que eu coloquei ... aí eu comecei a desabafar com os meus irmãos, com os meus filhos e coisa ... aí, quando eu consegui então a começar a fazer o curso, Meu Deus, cada vídeo que o professor de informática mandava, cada aula que ele mandava eu me desesperava mais, porque essa linguagem da informática é uma coisa muito complicada pra mim, muito, muito complicada.

Os desafios narrados pela professora Nice diante da utilização das tecnologias digitais; encontram respaldo em Pérez Gómez (2015), quando ele observa que se vive em uma era global de rápidas transformações com o aumento da interdependência e complexidade que vem causando uma mudança na forma de agir, pensar e comunicar. Para compreender essa mudança e utilizar os meios digitais propiciados pela internet, é preciso passar por uma nova alfabetização; é preciso "aprender a linguagem da tela", que chega a ser tão necessário como a alfabetização relacionada com a leitura e a escritura verbais.

Nice reflete acerca da sua experiência com a utilização das tecnologias e narra: 
Então, as vezes eu penso: Meu Deus do céu, eu tenho que me aposentar o mais rápido possível, porque, sabe o que que é: é a pedra no teu sapato! Pra mim, é essas novas tecnologias. Então, pensa, eu ter que elaborar toda uma aula, e não sabia entrar... eu sei que no fim, a minha nora veio aqui me ajudar, porque ela é coordenadora da educação infantil de uma escola da rede privada, ela também é professora né, então ela tá por dentro, eles também têm uma plataforma lá que eles estão tendo aula online, inclusive com os pequenos. Aí ela disse: Nice, queres que eu vá te ajudar? Eu disse: aí, vem, por favor! Então, ela me ajudou, ela veio sábado de manhã, domingo de manhã e veio ontem à noite. Então, eu me vejo hoje... meu deus como que eu vou dizer... ultrapassada! É, ultrapassada, porque eu não consegui acompanhar esse desenvolvimento da informática, tanto é que, ontem minha nora estava aqui, aí ela... fazia uma coisa e não dava certo, aí eu disse: “tá, Gi, mas como é que tu sabes que isso é assim e assim?" Ela disse: Nice, é porque a gente pratica todo dia, então sabe $[\ldots]$.

Na narrativa se faz presente a importância do trabalho coletivo nas escolas, entretanto, por conta do isolamento social, muitos docentes podem sentir-se desamparados nesse momento em que o "calor humano" não se faz presente. Igualmente, os docentes precisam encontrar outras formas de sanar suas dificuldades, entretanto, elas se tornam mais difíceis quando não há a presença de outro profissional fisicamente os auxiliando. Além disso, a professora expõe que recebeu auxiliou da sua nora, pois ela apresenta facilidade no manejo das tecnologias por utilizá-las cotidianamente. Por certo, infere-se que seriam necessários programas de formação continuada para contribuir com as dificuldades comumente vivenciadas por docentes que se licenciaram, sobretudo, antes dos anos 90, tendo em vista que a disseminação da tecnologia começou a ocorrer em meados da referida década (BORBA; OECHSLER, 2018).

A professora Nice dá sequência na sua narrativa acerca da utilização das plataformas digitais e expõe:

\footnotetext{
Aí, eu sei que fiquei esses dias trabalhando de manhã, de tarde e de noite fazendo coisa pra quando ela viesse me ajudar a postar ali na aula né, na plataforma do Moodle. Então eu tenho aula, estou mais calma hoje, hoje já passei o dia mais calma, porque eu tenho aula já pra duas semanas, ali já prontinhas, porque ela me ajudou já a colocar ali.
}

Observa-se na narrativa que o contato com os estudantes não ocorre diretamente, mas eles possuem o acesso às atividades desenvolvidas, mas virtualmente na plataforma Moodle criada pela própria Secretaria da Educação do município. Ressalva-se que as atividades são inseridas no Moodle e os estudantes podem ter acesso ao material acessando à plataforma. No entanto, as dúvidas podem ser sanadas pelo WhatsApp, conforme pode ser observado na narrativa quando ela expõe: 
Então assim, eu posto as aulas no Moodle e eu tenho um grupo de WhatsApp com os pais, com as crianças e então, se eles têm alguma dúvida, eles entram em contato comigo pelo WhatsApp. Eu também não adotei pra eles fazerem no Moodle as atividades, eles fazem em caderno, nos cadernos deles né, fotografam e mandam pra mim pelo Whats, então eu tenho corrigido as atividades deles pelo Whats, eles mandam as atividades, fotografam... [...] e assim a gente está conseguindo. De vez em quando eu mando áudio, eu falo com eles, sempre digo que estou com muita saudade deles, e eles também dizem que estão com saudades de mim. Ah, os pais relatam também que eles falam muito em mim e... eu faço também vídeo aula né, então eles acabam também me vendo explicar algum conteúdo novo.

O diálogo é mais frequente pelo WhatsApp e não pela plataforma digital que, como observado na narrativa da professora Nice, serve mais para a inserção de atividades. Justificase porque a maioria dos estudantes não possuem computador em casa, mas tem acesso ao WhatsApp pelo celular dos pais. Além disso, cinco estudantes não possuem nem o acesso à internet pelo celular, o que exige que eles se desloquem semanalmente até às escolas para pegarem as atividades impressas. Tais desafios, são narrados pela professora Nice:

Eu acho, que a maioria é só pelo celular, eles não têm computador eu acho, então, aí também o trabalho já se torna bem mais difícil né, porque no computador, tudo fica maior, fica melhor né! E, eu tenho cinco que não tem acesso à internet, então, eles vão toda a semana na escola pegar atividades impressas. Esses cinco, é claro, já são os mais... que não tem internet, são aquelas pessoas mais simples, crianças com mais dificuldade também. Então, essas atividades, não se tem um retorno esperado, está bem fraquinho desses cinco. Mas, dos que fazem pelo Moodle, está assim, uma média bem boa, até porque, eu fico cobrando né, quando tem atividade pra eles me devolverem, eu fico cobrando. E ... na medida do possível, eles vão mandando.

$\mathrm{Na}$ narrativa da professora Nice, observa-se um acentuado destaque para as desigualdades sociais presentes no país, que se torna mais evidente no momento atual, pois justamente as crianças que não possuem acesso à internet são "aquelas pessoas mais simples, crianças com mais dificuldade também". Tal constatação, faz lembrar o que Nóvoa (2009, p. 31) denomina de "compromisso social” quando expõe que "educar é conseguir que a criança ultrapasse as fronteiras que, tantas vezes, lhe foram traçadas como destino pelo nascimento, pela família, ou pela sociedade”. O autor vai ainda mais adiante na discussão, quando reflete que "o pior que podemos fazer às crianças, sobretudo às crianças dos meios mais pobres, é deixá-las sair da escola sem uma verdadeira aprendizagem” (NÓVOA, 2009, p. 60).

Desse modo, o que preocupa são as condições sociais que as cinco crianças mencionadas estão enfrentando, sobretudo num momento tão difícil como o que se está vivendo. Porém, infelizmente, essa realidade está se repetindo em muitas cidades e escolas do país. Entretanto, do mesmo modo, não há como negar que os docentes estão fazendo o que podem, com os recursos que possuem, inclusive, a professora Nice narra: "mas a gente está conseguindo 
produzir alguma coisa [...], estamos trabalhando e estamos fazendo assim o possível e o impossível pra dar certo".

Nice, dá prossegue sua narrativa refletindo:

Eu acho que... antes de eu me aposentar não precisava ter acontecido essa pandemia pra mim ainda passar por isso, porque, ah, dando aula, eu buscava as tecnologias, mas aí, eu tinha o meu suporte lá na escola, se eu precisava de qualquer coisa, eu pedia ajuda. Tanto é, que, nunca ninguém se negou, as pessoas que são mais “experts” né, na informática, estavam ali na sala de professores, as vezes numa aula de hora atividade, eu pedia ajuda [...].

Vaillant e Marcelo (2012) observam que as tecnologias digitais são complexas para se compreender e para serem utilizadas, pois mudam com muita rapidez, sendo que essa instabilidade surge quando o conhecimento requerido para utilizá-las nunca termina, pois as tecnologias mudam continuamente. A instabilidade provocada por elas requer que os professores estejam em constante formação, continuamente aprendendo o que, por vezes, pode gerar frustração. Os autores observam ainda que para atuar no e-learning, é necessário possuir uma competência tecnológica, ou seja, possuir conhecimentos necessários para gerir e empregar todos os recursos imprescindíveis para a formatação e desenvolvimento de ferramentas de comunicação. Também requer dos docentes o conhecimento e o uso da plataforma que se desenvolve as atividades e os efeitos de adaptá-la aos estudantes.

Apesar dos desafios já mencionados pela professora entrevistada, ela expõe que -o apoio dos pais na realização das atividades tem sido fundamental.

Eu vejo assim, que os pais estão colaborando né... porque, lógico se os pais não fizerem, não ficarem em cima, eles também não vão se lembrar que eles têm... por exemplo, tem dias que eles têm aula comigo só, mas tem dias que eles têm Arte, Educação Física, Ciências, Ética, então, não é só comigo né... mas, quando a gente tem pais assim, companheiros, pais que ajudam, a coisa funciona melhor!

Nóvoa (2009, p. 67) reflete que "nada será conseguido se a sociedade não apoiar o trabalho escolar". Por certo, quando as famílias apoiam o trabalho dos professores, nas palavras da professora Nice "a coisa funciona melhor!"

Nice continua sua narrativa e expõe como se sente enquanto professora prestes a se aposentar e vivenciando uma pandemia mundial. Ela narra: "é uma coisa diferente, nos meus 51 anos de magistério, é uma coisa que eu nunca passei, uma nova experiência né! Mas, é bom a gente aprender essas coisas também, é bom a gente estar assim em situações difíceis também e a gente vê que tem solução pra tudo...”.

Ela menciona que o que mais sente falta, é 
desse contato da gente, desse "olho no olho", deles virem me abraçar e assim, eles me elogiam muito, que estou muito bonita, então, sabe... isso tudo faz falta, é aquele carinho né, que a gente tem... de manhã, quando eles vinham já... "Oi Prô Nice; Oi Prô Nice", então, isso tudo faz falta, mas, vamos ver se no ano que vem, em março ou fevereiro começa... eu quero ver se eu pego essa turma de novo, porque provavelmente eles vão pedir até pro professor ficar com a mesma turma, porque sabem como é que a coisa funcionou né, durante esse tempo todo.

Nóvoa (2020), mais recentemente em uma Webconferência ministrada, reflete sobre a educação no momento presente e expõe que as ferramentas digitais vêm sendo utilizadas mais do que nunca, mas que elas não poderão substituir a figura do professor e discorre que esta situação emergencial não é uma solução do futuro, porque a escola física é indispensável aos estudantes, e é nela que se estabelece um espaço de convívio, de vínculo, de relação humana.

Para finalizar sua narrativa, Nice reflete ainda:

Tá, tenho muita experiência, tenho! Mas, estou defasada nessa parte, então, é como eu digo, a gente aprende todos os dias, então, as pessoas sempre, até eu acho que as vezes fazem demais: Então, ah, "porque tu és o meu espelho”, muitas pessoas dizem isso, mas, não... eu acho que não. Eu me espelho em muitas delas que são bem mais jovens do que eu, com menos experiência, mas tem assim, toda uma dinâmica diferente né, de dar aula, de criar, de procurar, de pesquisar. E eu me vejo muito amarrada, porque eu não sei ir lá fazer uma pesquisa e buscar uma coisa e trazer isso pra sala de aula, eu preciso sempre de ajuda. Então, eu... eu me vejo assim nesse final. Não pensei que eu iria sentir tanto isso, mas a coisa andou muito ligeiro né, andou muito ligeiro, nos últimos agora dois, três anos, mudou muito.

Corroborando com a professora Nice, observa-se que as coisas mudaram muito ligeiroe que a pandemia ocasionada pelo coronavírus acelerou essa transformação. Pérez Gómez (2015, p. 25) reflete que "com relação às tecnologias digitais, "passou pouco tempo e tudo avança rapidamente [...]", e as escolas, por conseguinte, devem se transformar em poderosos cenários de aprendizagens onde os estudantes investigam, compartilham, aplicam e refletem sobre o conhecimento (PÉREZ GOMÉZ, 2015).

No entanto, para que os estudantes possam investigar, compartilhar, produzir e refletir sobre o conhecimento, antes de tudo, é necessário que seus professores tenham condições favoráveis para utilizar as ferramentas digitais, e isso será possível quando as formações continuadas forem oferecidas aos docentes levando em consideração as reais necessidades apresentadas por eles.

Vaillant e Marcelo (2012) observam que a literatura sobre os processos de mudança mostra que as inovações podem surgir de dentro ou fora da escola, mas, para que se sustentem, é imprescindível que sejam dadas algumas condições, já que a inovação pode surgir com certa facilidade, mas a ausência de recursos e a falta de reconhecimento são iminências contínuas para sua sustentabilidade. Marcelo (2001) expõe que a simples incorporação das tecnologias 
nas escolas não é sinônimo de efetivos resultados alcançados, e que um dos aspectos mais atrativos das novas tecnologias é o impacto no ambiente de aprendizagem, pois elas deveriam incorporar uma mudança na forma de organizar o ensino e a aprendizagem. Tudo isso requer que os docentes estejam mais centrados na aprendizagem que no ensino, portanto, deve haver um cuidado na organização e disposição dos conteúdos de aprendizagem.

Entretanto, há um outro fator determinante nesse processo, pois não basta que os professores tenham formações para utilizar as ferramentas digitais, é preciso que sejam dadas as condições para que estudantes das classes menos privilegiadas possam ter acesso à internet e, só assim, como elucidado por Vaillant e Marcelo (2012) no início desta pesquisa, poder-seá assim ter garantido como eixo central, o direito de aprender que todos possuem.

\section{Considerações finais}

Conforme evidenciado na narrativa da professora participante desta pesquisa, utilizar as tecnologias mediante e-learning tornou-se um desafio para ela que, estando na escola, recorria ao auxílio de professores com mais facilidade na utilização de tais ferramentas, fazendo com que se reflita sobre a formação continuada no processo educacional. Infere-se, portanto, que há uma defasagem em políticas públicas e em programas de formação continuada, que ofereçam aos professores conhecimentos para que se sintam seguros ao utilizar as ferramentas digitais, visualizando-as como uma aliada no processo de ensino e aprendizagem dos estudantes.

Igualmente, dada a urgência do momento, ressalta-se que os professores tiveram que se reinventar num momento tão difícil e de significativas mudanças na educação. Do mesmo modo, não há como "fazer vistas grossas", ao acentuado destaque das desigualdades sociais presentes no país, pois os desafios educacionais são ainda maiores para as crianças que não possuem acesso à internet. Nas palavras de Nóvoa (2019), é tempo de uma metamorfose da escola. Entretanto, o que preocupa são os caminhos que essa metamorfose seguirá. Que ela possa, de fato, contribuir para uma educação elucidada por Vaillant e Marcelo (2012) em que o eixo central é o direito de aprender que todos os estudantes possuem.

\section{Referências}

ANDRÉ, Marli. O que é um estudo de caso qualitativo em educação? Revista da FAEEBA Educação e Contemporaneidade, Salvador, v. 22, n. 40, p. 95-103, 2013. 


\section{Dialogia}

BRUNS, Juliana Pedroso; RAUSCH, Rita Buzzi. Narrativas de uma professora em final de carreira: a educação frente à pandemia

BARDIN. Laurence. Análise de conteúdo. Tradução: Luís Antero Reto; Augusto Pinheiro. São Paulo: Edições 70, 2016.

BRASIL. Diário Oficial da União. Mensagem $n^{\circ}$ 93. 2020a. Disponível em: https://www.in.gov.br/en/web/dou/-/despacho-do-presidente-da-republica-248641738. Acesso em: 21 maio. 2020.

BRASIL. Diário Oficial da União. Portaria nº 343, de 17 de março de 2020. 2020b. Disponível em: https://abmes.org.br/arquivos/legislacoes/Portaria-mec-343-2020-03-17. Acesso em: 21 maio. 2020.

BOGDAN, Robert C.; BIKLEN, Sari Knopp. Investigação qualitativa em educação: uma introdução a teoria aos métodos. Porto: Porto Ed, 1994. 336 p.

BORBA, Marcelo de Carvalho. OECHSLER, Vanessa. Tecnologias na educação: o uso dos vídeos em sala de aula. R. bras. Ens. Ci. Tecnol., Ponta Grossa, v. 11, n. 2, p. 391-423, mai./ago. 2018.

MARCELO, Carlos. Aprender a Enseñar para la Sociedad del Conocimiento. Revista Complutense de Educación, vol. 12 n. 2, p. 531-593, 2001.

NÓVOA, António. Os professores e sua formação num tempo de metamorfose da escola. Educação \& Realidade, Porto Alegre, v. 44 n.3, p. 1-15. 2019. Disponível em: https://www.scielo.br/scielo.php?script=sci_arttext\&pid=S2175-62362019000300402. Acesso em: 20 maio. 2020.

NÓVOA, António. Professores: imagens do futuro presente. Lisboa: Educa, 2009. 96 p.

NÓVOA, António. Webconferência - Formação de professores em tempo de pandemia. 2020. Disponível em: https://www.youtube.com/watch?reload=9\&v=ef3YQcbERiM Acesso em: 20 jul. 2020.

PRADO, Guilherme do Val Toledo. SOLIGO, Rosaura. Memorial de Formação - quando as memórias narram a história da formação. In: PRADO, Guilherme do Val Toledo. SOLIGO, Rosaura (Orgs.). Porque escrever é fazer história: revelações, subversões, superações. Campinas, SP: Editora Alínea, 2007. p. 45-60.

PERÉZ GÓMEZ, Ángel I. Educação na era digital: a escola educativa. Tradução: Marisa Guedes; revisão técnica: Bartira Costa Neves. Porto Alegre: Penso, 2015. 192 p.

VAILLANT, Denise. MARCELO, Carlos. Ensinando a ensinar: as quatro etapas de uma aprendizagem. Curitiba: Ed. UTFPR, 2012. 242 p.

Recebido em: 10 ago. 2020/ Aprovado em: 13 nov. 2020

Cite como

(ABNT NBR 6023:2018) 


\section{Dialogia}

BRUNS, Juliana Pedroso; RAUSCH, Rita Buzzi. Narrativas de uma professora em final de carreira: a educação frente à pandemia

BRUNS, Juliana Pedroso; RAUSCH, Rita Buzzi. Narrativas de uma professora em final de carreira: a educação frente à pandemia. Dialogia, São Paulo, n. 36, p. 102-115, set./dez. 2020. Disponível em: https://doi.org/10.5585/dialogia.n36.17883.

\section{American Psychological Association (APA)}

Bruns, J. P., \& Rausch, R. B. (2020, set./dez.). Narrativas de uma professora em final de carreira: a educação frente à pandemia. Dialogia, São Paulo, 36, p. 102-115.

https://doi.org/10.5585/dialogia.n36.17883. 